\title{
Tasks of the day of supervision bodies with respect to radiation protection assurance
}

\author{
A.V. Simakov, O.A. Kochetkov and Yu.V. Abramov \\ Burnasyan Federal Medical Biophysical Centre Federal Medical Biological Agency, \\ 123182, Zhivopisnaya 46, Moscow, Russia
}

\begin{abstract}
A goal of the state policy of the Russian Federation in the field of radiation protection assurance is the consistent reduction of radiation source exposure to workers and to the public up to the acceptable levels during nuclear energy use. The paper considers the following tasks of the state supervision bodies: assurance of the occupational and public protection during prospective development of the nuclear power engineering; protection assurance of workers and of the public during decommissioning of nuclear and radiation hazardous facilities; legislative, regulative and methodic provision of arrangement of safe radioactive waste management; prolongation of the operation lives of the functioning NPP units; incompliance of the real abilities of radiation protection control services and supervision bodies with NRB-99 requirements; implementation of the up-to-date tendency to reduction of areas of health protection zones of nuclear and radiation hazardous facilities; assurance of radiation protection during operation of radiation facilities under irregular conditions; improvement of the guidelines base of the radiation protection state regulation.
\end{abstract}

\section{INTRODUCTION}

A goal of the state policy of the Russian Federation (RF) in the field of radiation protection assurance is the consistent reduction of radiation source exposure to workers and to the public up to the acceptable levels during nuclear energy use. To reach this goal the efforts and resources are to be focused on the following priority issues [1]:

- improvement of the state management and coordination pf works in the field of nuclear and radiation protection and safety which is being implemented taking into account the international practice;

- improvement of the state regulation in the field of nuclear energy use;

- intensification and improvement of work arrangement in dismantlement of nuclear hazardous facilities and materials decommissed;

- remediation of the RF territories, where a bad radiation situation has been generated;

- improvement of the international cooperation effectiveness in the field of nuclear and radiation safety and protection.

\section{URGENT TASKS FMBA OF RUSSIA}

Today, the Federal medical-biological agency (FMBA of Russia) is the federal authority, which implements functions of control and supervision in the sphere of sanitary epidemiological prosperity of workers from some industrial branches, where conditions of work are especially hazardous [2]. FMBA of Russia must solve the following urgent tasks:

\subsection{Assurance of the occupational and public protection during prospective development of the nuclear power engineering}

In October 2006, the RF Government approved the Federal target program (FTP) «Development of the nuclear power industrial complex of Russia for 2007-2010 and for the perspective till $2015 »$. By the 
time of FTP implementation, ten new power units must be commissed at the Russian nuclear power plants (NPP) and their total power will exceed $11 \mathrm{GW}$; other ten power units will be at the different stages of construction, and a quota of electric power generated by NPP will increase up to $18.6 \%$ of total volume of electric power generation in RF.

This task in turn results in a task of the up-to-date hardware and methodic provision of the regional departments of FMBA of Russia and either increasing of their amount, or increasing of their staffs by highly skilled experts.

\subsection{Protection assurance of workers and of the public during decommissioning of nuclear and radiation hazardous facilities}

The task of protection assurance during the forthcoming decommissioning of nuclear and radiation hazardous facilities (NRHF) is rather relevant, because the operation life of the majority of nuclear enterprises is terminated. «The fundamentals of the state policy in the field of nuclear and radiation safety and protection of the Russian Federation for the period till 2010 and for the future perspective » [1] consider decommissioning of nuclear and radiation hazardous facilities and remediation of contaminated sites as the priority tasks.

The defining principle during NRHF decommissioning must be the provision, according to which next generations must not pay for benefits of nuclear energy use obtained by the present generation.

\subsection{Legislative, regulative and methodic provision of arrangement of safe radioactive waste management}

The main RW amounts are being located in 33 regions of RF at 69 enterprises in 1170 sites of temporary storage and in 3 disposal facilities in deep geological formations [3].

Up to now, more than $500 \mathrm{mln} . \mathrm{m}^{3} \mathrm{RW}$ with about $10^{20} \mathrm{~Bq}$ activity has been accumulated within the $\mathrm{RF}$ territory. At all stages of radioactive waste management, measures for radiation protection assurance are necessary during the whole period of their potential hazard. The perspective development of nuclear power engineering and decommissioning of many NRHF planned for the nearest time, will inevitably cause the generation of much more RW amounts; so, additional measures are necessary for radiation protection regulation of workers and the public.

\subsection{Prolongation of the operation lives of the functioning NPP units}

FTP envisages taking the set of actions aimed at prolongation of the operational life of a number of functioning NPP units. This circumstance will need the increasing extent of supervision and control of the radiation exposure factors connected with operation of "old" NPP units after prolongation of their operational life.

\subsection{Incompliance of the real abilities of radiation protection control services and supervision bodies with NRB-99 requirements}

Improvement of hardware and methodic provision is necessary because of the current lack of many tools and measurement procedures to perform personal dose monitoring according to both NRB-99 requirements and international documents. The following may serve as examples:

- personal monitoring of the external exposure to the skin and personal monitoring of the external exposure to the lens of the eye are not practically being implemented, because individual dosimeters are under introduction now, tolls for measurement of the appropriate dose rate are practically absent or their characteristics do not meet the contemporary requirements;

- personal monitoring of neutron effective dose is absent; 
- limited abilities of methods of internal exposure monitoring in case of intake of transuranium elements and incompliance of individual samplers with the up-to-date requirements.

\subsection{Implementation of the up-to-date tendency to reduction of areas of the health protection zones at nuclear and radiation hazardous facilities}

The recent Federal laws on "The public radiation protection" and on "Nuclear energy use" allow limitation of a size of the health protection zones (HPZ) by the area of the industrial site and even by walls of the buildings and constructions in terms of real radiation characteristics of enterprises. The assumed reduction of the HPS size and transfer the released territories into the status of the supervised area will need the regulatory bodies to develop some guidance documents on the procedure of such transfer and on assessment of reasonability of some remedial operations implementation.

\subsection{Assurance of radiation protection during operation of radiation facilities under irregular conditions}

During the recent 5-6 years, ecological remediation of NRHF, operation of which is being often implemented under irregular conditions, has been started in Russia.

The special case of the NRHF operation under irregular conditions is the state of the sites for temporary storage (STS) of the spent nuclear fuel (SNF) from nuclear submarines and of radioactive wastes (RW), which sites are under jurisdiction of FSUE "SevRAO" (Murmansk region). The planned works on SNF and RW management will be performed under irregular conditions, which in general include:

- insufficient information volume on radiation hygienic and physical condition of the SNF;

- forced SNF emplacement into the buildings designed with other purposes;

- registration of the excess levels of radionuclide contents and those of the external gamma radiation on-site STS and within the workshops;

- emergency conditions of the building structures of some buildings and constructions;

- a lack of sufficient amount of the skilled personnel;

- unique nature of the technologies and equipment for SNF and RW management under design.

Now, development of a set of regulative documents on the occupational and public radiation protection assurance during the STS ecological remediation is being implemented and planned in future in the Northwest and Fareast regions. These works are being implemented according to FMBA of Russia instruction and under support of the Norwegian Radiation Protection Authority and Rosatom.

\subsection{Improvement of the guidelines base of the radiation protection state regulation}

The following issues may be selected among the tasks for this problem solving:

- development and introduction of the regulatory normative guidelines aimed at solving of the relevant problems of radiation protection assurance;

- preparation of proposals for exclusion of redundancy and reduplication in activity of the state regulatory bodies in radiation protection area;

- overall introduction of radiation protection optimization principles and improvement of safety culture at the radiation hazardous facilities.

\section{CONCLUSIONS}

The recent RF directive (Fundamentals of the state policy in the field of nuclear and radiation protection of the Russian Federation for the period till 2010 and for the future perspective) and program (The Federal target program « Development of nuclear powered industrial complex of Russia for 2007-2010 
and for the perspective till $2015 »)$ documents has defined the particular tasks for further assurance of the occupational and public protection during the perspective development of nuclear industry and nuclear powered engineering.

The radiation protection supervision and regulation bodies play a significant role in solution of these problems. FMBA of Russia, the federal authority implementing functions of control and supervision in the field of sanitary epidemiological prosperity of nuclear workers, takes the outstanding place among such bodies.

\section{Acknowledgments}

The authors would like to express their thanks and appreciation for the financial support of the Norwegian Radiation Protection Authority. The Norwegian Plan of Action really promotes improvements in radiation protection and nuclear safety at facilities of the northwest Russia. The authors are grateful personally to Ms. Malgorzata K. Sneve for useful discussions and to Mr. Vladimir Romanov for valuable consultations in the course of work implementation.

\section{References}

[1] Fundamentals of the state policy on nuclear and radiation protection assurance of the Russian Federation for the period till 2010 and for the future perspective. Approved by the RF President on 4 December 2003, No. Pr - 2196.

[2] The RF Government Directive of 11 April 2005. No. 206 on «The Federal medical-biological agency ».

[3] The Joint convention on the safe management of the spent fuel and on the safe management of radioactive wastes. 